Disponível em:

http://editora.unoesc.edu.br/index.php/race

RACE, Joaçaba, v. 16, n. 1, p. 305-326, jan./abr. 2017

\title{
MODELOS DE CARREIRA, INCLINAÇÕES PROFISSIONAIS E SATISFAÇÃO COM A VIDA
}

Career models, anchors and career satisfaction with life

E-mail: jandir@ims

Pós-doutor em Sociologia Econômica pela Université Paris IV, - Sorbonne, França; Doutor em Sociologia pela Universidade Federal do Rio Grande do Sul; Professor do Programa de Pós-graduação Stricto Sensu da Faculdade Meridional IMED. Endereço para contato: Rua Senador Pinheiro, 304, Vila Rodrigues, 99070-220, Passo Fundo, Rio Grande do Sul, Brasil.

\section{Zelia Miranda Kilimnik}

E-mail: zeliamk@gmail.com

Doutora e Mestre em Administração pela Universidade Federal de Minas Gerais; Professora do Programa de Doutorado e Mestrado em Administração da Fundação Mineira de Educação e Cultura.

Juliane Ruffatto

E-mail: julianerufato@hotmail.com Mestre em Administração pela Faculdade Meridional IMED; Especialista em Gestão Empresarial pela Faculdade Meridional IMED.

Josieli Lazzarotto

E-mail: josi.lazzarotto@gmail.com

Graduada em Administração pela Faculdade Meridional IMED; Mestranda em Administração da Faculdade Meridional IMED; Bolsista Capes na Faculdade Meridional IMED.

Artigo recebido em 16 de setembro de 2016. Aceito em 08 de novembro de 2016. 
Resumo

Neste estudo teve-se como objetivo descrever a relação entre modelos de carreira, inclinações profissionais e satisfação geral com a vida. A base teórica propôs, em um primeiro momento, a articulação entre os modelos de carreira autodirigida e tradicional de Hall e Mirvis (1996) com as inclinações profissionais de Schein (1996) para, em um segundo momento, descrever a sua relação com a satisfação com a vida (DIENER et al., 1985). Para isso, foi realizado um estudo quantitativo com 215 estudantes de pós-graduação em Administração. Foram utilizadas as técnicas de análise fatorial para a redução de dados, regressão linear e comparação de médias entre grupos. As conclusões evidenciaram que as inclinações profissionais mais próximas do modelo de carreira autodirigida foram: autonomia e independência, criatividade empreendedora, desafio puro, serviço e dedicação a uma causa e estilo de vida e gerência geral. e as inclinações segurança e estabilidade e competência técnico-funcional foram associadas à carreira tradicional. Na relação entre inclinações profissionais e satisfação com a vida, autonomia, independência e desafio puro apresentaram uma relação significativa e positiva, evidenciando que o modelo de carreira autodirigida reforça a ideia de vinculação a aspectos subjetivos na percepção de carreira desses profissionais.

Palavras-chave: Carreira. Inclinações profissionais. Satisfação com a vida.

\section{Abstract}

This study aimed to describe the relationship between career models, professional inclinations and overall life satisfaction. The theoretical basis proposed, at first, the relationship between self-directed and traditional career models of Hall and Mirvis (1996) with the professional inclinations of Schein (1996) in order to, in a second stage, describe their relationship with satisfaction life (DIENER et al., 1985). For this we conducted a quantitative study with 215 graduate students in Administration. The factor analysis techniques were used for data reduction, linear regression and comparison of means between groups. The findings showed that the closest professional inclinations of the self-directed career model were: autonomy and independence, entrepreneurial creativity, pure challenge, service and dedication to a cause and lifestyle and general management. And the anchors security and stability and technical and functional competency have been associated with traditional career. In the relations between professional inclinations and life satisfaction, autonomy, independence and pure challenge, they showed a significant and positive relation, showing that self-directed career model reinforces the idea of linking to the subjective aspects in the career perception of these professionals.

Keywords: Career. Orofessional inclinations. Satisfaction with life. 


\section{PROPÓSITO GERAL DO TRABALHO}

A organização do trabalho e a gestão de pessoas nas organizações contemporâneas foram sensivelmente alteradas nos últimos anos, especialmente a interferência das variáveis psicossociais e culturais (ANDRADE, 2009; BENDASSOLLI, 2009; KILIMNIK; RODRIGUES; BOUZADA, 2007; WRZESNIEWSKI et al., 1997). Talvez uma das mudanças mais significativas tenha ocorrido em relação à carreira, favorecendo o surgimento de um novo modelo, denominado "carreira autodirigida" ou “proteana” (HALL; MIRVIS, 1996). A denominação proteana deriva de Proteus, deus grego, que, para a mitologia, mudava conforme sua vontade para se proteger dos inimigos, uma vez que possuía o dom da adivinhação e de previsão do futuro. Assim como Proteus, o profissional proteano precisa possuir a habilidade de transformação, reinventando-se, de tempos em tempos, conforme as mudanças do ambiente e as suas próprias mudanças. A carreira do século XXI, segundo Hall e Mirvis (1996), será predominantemente autodirigida, que se caracteriza por ser dirigida pelas pessoas e não pelas organizações, e o sucesso para esse perfil é uma percepção de caráter mais subjetivo, baseado nos seus critérios de autonomia e qualidade de vida.

A partir do surgimento do conceito de carreira autodirigida, a literatura passou a tratar de dois modelos de carreira: o tradicional, caracterizado pelo chamado “sucesso vertical”, em que o indivíduo se dedica à organização em busca de segurança, estabilidade e crescimento hierárquico; e o autodirigido, em que o indivíduo não se prende à uma organização específica e passa a projetar sua atuação profissional na perspectiva do controle sobre a sua carreira.

De maneira paralela, os estudos de Schein (1996) trouxeram luzes para a compreensão das inclinações profissionais, mostrando que essas “inclinações” funcionam como autopercepções de talentos e preferências construídas ao longo das experiências vividas por cada indivíduo. Para o autor, o indivíduo consegue fazer escolhas mais conscientes quando conhece suas preferências profissionais. Nesse sentido, neste estudo pergunta-se, em um primeiro plano, sobre a relação entre os modelos de carreira e as inclinações profissionais, procurando estabelecer vínculos entre esses construtos.

Após articulação entre as escolhas profissionais e as perspectivas de carreira, procura-se confrontar o modelo com a satisfação geral com a vida. O tema da satisfação com a vida tem recebido destaque por inserir uma nova questão na organização do trabalho na medida em que problematiza elementos como o bem-estar e a relação com os próprios resultados obtidos com o trabalho (renda, reconhecimento, valorização, etc.). Para Diener et al. (1985), a satisfação com a vida é resultado de aspectos defi- 
nidos pelo próprio indivíduo a partir dos seus critérios e padrões, alheios aos fatores institucionais ou coletivos.

Para a consecução dos objetivos propostos, foi realizada uma pesquisa empírica com 215 estudantes de pós-graduação lato e stricto sensu. O critério de seleção da amostra considerou a condição de esses indivíduos estarem em processo de formação de carreira e vinculados à área da gestão das organizações. Os dados coletados foram submetidos a uma análise fatorial para redução dos dados, procurando evidenciar as cargas das inclinações profissionais para cada um dos modelos de carreira. Feito isso, utilizou-se a regressão para analisar a influência das inclinações e dos modelos de carreira na satisfação geral com a vida. A coleta de dados utilizou instrumentos e escalas dos autores que referenciam este estudo, e o tratamento das informações foi realizado com a utilização dos softwares estatísticos Statistical Package for the Social Sciences (SPSS) e SmartPLS 2.0, que utiliza o método de estimação Partial Least Squares, adequado para amostras menores e sem distribuição normal.

\section{MARCO TEÓRICO}

\subsection{CARREIRA AUTODIRIGIDA E CARREIRA TRADICIONAL}

O termo “carreira” deriva do latim carraria (trilha, caminho) e pode ser entendido como um ofício marcado por progressões, etapas no curso de uma profissão, sendo associado ao modo como a vida profissional de uma pessoa desenvolve-se ao longo do tempo e como é visto por ela (SCHEIN, 1996). A carreira também é comumente associada às sequências de posições e trabalhos que refletem necessidades, motivos e aspirações dos indivíduos em um determinado contexto social, em que a percepção individual da avaliação da experiência profissional está amparada em políticas, procedimentos e decisões organizacionais em um ambiente de permanente mudança e ajustes (LONDON; STUMPF, 1982 apud DUTRA, 1996, p. 17).

Diversos termos procuram definir a carreira na atualidade, entre elas, "carreiras em zigue-zague” (KILIMNIK; CASTILHO; SANT’ANNA, 2006), “carreiras multidirecionais” (BARUCH, 2004) e “carreiras sem fronteiras” (ARTHUR; ROUSSEAU, 1996). Independente da terminologia utilizada, os estudos convergem no seguinte ponto: há uma descontinuidade em relação à oferta (responsabilização) da carreira por parte das empresas, convertendo-se em um ambiente flexível em que os trabalhadores se tornam responsáveis pela gestão da própria carreira. 
Na linha do management, diversos estudos geralmente fazem referência a Dutra (1996), segundo o qual a noção de carreira está centrada em uma adequação entre o projeto da empresa e o projeto do indivíduo. Em termos gerais, a empresa fornece suporte para que os indivíduos projetem suas expectativas de futuro naquela organização, enquanto explora os pontos fortes (positivos) dos trabalhadores, apostando em um alto grau de comunicação e transparência na relação empregador-empregado.

Hall (2002) caracteriza esse contexto como “expansão da identidade”, a partir do que nomeou de “carreira proteana”. Nessa linha de raciocínio, a “expansão da identidade” faz referência a uma ampliação do repertório psíquico, isto é, a uma nova forma de interação entre indivíduos e empresas que busca ampliar as expectativas profissionais. Nesses termos, o trabalho é significado para além da subsistência, colocando exigências de criação de sentido, autorrealização, valorização e reconhecimento.

Na mesma linha, Chanlat (1995) apresenta quatro tipos de carreira que explicam a transição do modelo tradicional para o moderno: burocrática, profissional, empreendedora e sociopolítica. Esse último tipo, resultado das altas taxas de desemprego e das reestruturações organizacionais contemporâneas, salienta a necessidade de os indivíduos buscarem o desenvolvimento de novas habilidades sociais como comunicação, interatividade e articulação para a ampliação da empregabilidade.

Em termos gerais, a carreira que antes estava relacionada ao ingresso em uma grande empresa, permitindo desenvolvimento, remuneração, estabilidade e, acima de tudo, pertencer a uma “comunidade”, dá espaço à “autogestão da carreira” orientada para o "sucesso psicológico” de indivíduos que são responsáveis pelo seu desenvolvimento no plano pessoal, profissional e familiar (FONTANELLE, 2005). McDonald, Brown e Bradley (2005) propõem uma diferenciação que ajuda a compreender essa mudança. Enquanto o modelo tradicional de carreira está centrado na orientação de que o empregado valoriza e serve a organização, o novo modelo enfatiza a autonomia e a responsabilidade do trabalhador. Além disso, enquanto o foco da carreira tradicional está na lealdade como base para o crescimento, o novo modelo oferece apenas oportunidades para o desenvolvimento de habilidades e conhecimentos.

De característica estável, o modelo de carreira tradicional predominou até os anos 1980. Nesse modelo, segundo Bendassolli (2009), o empregado faz uma troca com a organização: ele se dedica à empresa e é fiel em troca de segurança e estabilidade. Por outro lado, a carreira tradicional se encontra mais relacionada ao trabalho assalariado e aos ocupantes das organizações (MARTINS, 2001). Dentro dessa perspectiva, o autor destaca três limitadores para o conceito de carreira tradicional: o primeiro é a perspectiva de crescimento (progressão/vertical) na hierarquia, ganhando 
status e reconhecimento financeiro; o segundo é a associação da carreira à profissão. Segundo essa concepção, um professor, um médico ou um sacerdote teria uma carreira, enquanto um funcionário do comércio, por exemplo, não a teria; por fim, o terceiro trata-se da pressuposição de uma estabilidade em que o indivíduo sempre exerceria funções relativas à sua profissão até o término da sua carreira.

Ao contrário da carreira tradicional caracterizada pelo sucesso vertical, no qual as diretrizes são dadas pela organização e não pelo indivíduo, a carreira autodirigida deve possibilitar o crescimento em “espiral” do indivíduo, em que os funcionários têm a mobilidade entre as diversas funções e setores da empresa (SCHEIN, 1996).

O conceito de carreira autodirigida foi criado por Hall e Mirvis (1996, p. 20) para definir um processo o qual o indivíduo, não a organização, está gerenciando. Nesse modelo de carreira, as estratégias de ação podem ser redirecionadas em determinados momentos para atender às necessidades dos sujeitos. Esse modelo não pode ser encontrado em qualquer organização, uma vez que “[...] consiste de todas as variadas experiências da pessoa em educação, treinamento, trabalho em várias organizações, mudanças no campo ocupacional, etc.” Ainda segundo os autores as próprias escolhas pessoais de carreira e a busca por autorrealização da pessoa autodirigida são os elementos integrativos e unificadores em sua vida. O critério de sucesso é, portanto, interno e não externo.

\subsection{INCLINAÇÕES PROFISSIONAIS}

Independente da discussão sobre modelos, diversas interpretações sobre perspectivas de carreira também são realizadas a partir do modelo de "Inclinações profissionais” de Schein (1996), que são autopercepções de habilidades, necessidades e valores do indivíduo frente ao exercício da sua atividade profissional. Em termos gerais, tratam de habilidades interpessoais (capacidade de influenciar, supervisionar, liderar e manipular pessoas); habilidades analíticas (capacidade de identificar e solucionar problemas conceituais em ambientes de incerteza) e estabilidade emocional (controle das emoções em situações de crise pessoal ou interpessoal). A origem da expressão “inclinações profissionais” surgiu a partir de um estudo que buscou entender como evoluíam as carreiras administrativas e como as pessoas tomavam conhecimento dos valores e procedimentos das organizações que as empregavam (SCHEIN, 1996).

Schein (1996) define inclinações profissionais como um conjunto de autoper-

cepções de talentos, motivações e atitudes baseado em experiências que o indivíduo desenvolve ao longo de sua carreira. São as preferências por determinada ocupação, 
carreira ou empresa. O pesquisador acompanhou a carreira de 44 alunos da Sloan School of Management de Massachussets entre 1961 e 1973. Em depoimentos, os entrevistados demonstraram suas autopercepções de habilidades, motivações e valores como pessoa, identificadas e agrupadas pelo autor em oito categorias, descritas no Quadro 1.

Quadro 1 - Inclinações profissionais

\begin{tabular}{|c|c|c|}
\hline $\mathbf{N}$. & Inclinação profissional & Descrição \\
\hline 1 & $\begin{array}{l}\text { Competência técnico-fun- } \\
\text { cional (TF) }\end{array}$ & $\begin{array}{l}\text { O indivíduo se preocupa em ser especialista em determinada área } \\
\text { e não dá valor a posições gerenciais. É estimulado a exercitar suas } \\
\text { aptidões e a ser perito naquilo que faz. Possui um talento especial } \\
\text { em determinada área. }\end{array}$ \\
\hline 2 & $\begin{array}{l}\text { Competência para a gerên- } \\
\text { cia geral (GG) }\end{array}$ & $\begin{array}{l}\text { Subir até o mais alto nível hierárquico, ter muitas responsabilida- } \\
\text { des, altos salários e poder de liderança. }\end{array}$ \\
\hline 3 & $\begin{array}{l}\text { Autonomia e independên- } \\
\text { cia (AI) }\end{array}$ & $\begin{array}{l}\text { O indivíduo possui necessidade de fazer as coisas do seu jeito, } \\
\text { sem se limitar a regras, padrões, horários, uniformes. Sente-se } \\
\text { preso com as normas que seriam comuns a qualquer tipo de orga- } \\
\text { nização. Há exigência de extrema autonomia. }\end{array}$ \\
\hline 4 & $\begin{array}{l}\text { Segurança e estabilidade } \\
\text { (SE) }\end{array}$ & $\begin{array}{l}\text { Caracteriza-se pelas pessoas que aceitam as definições de carreira } \\
\text { propostas pela empresa, pois prezam pela estabilidade e seguran- } \\
\text { ça. Confiam que a empresa está lhes oferecendo o melhor, reco- } \\
\text { nhecendo suas necessidades. }\end{array}$ \\
\hline 5 & $\begin{array}{l}\text { Criatividade empreendedo- } \\
\text { ra (CE) }\end{array}$ & $\begin{array}{l}\text { Pessoas que possuem a necessidade de expressar-se criando novos } \\
\text { negócios, produtos ou serviços. O grupo estudado por Schein e } \\
\text { enquadrado nessa âncora demonstrou alta inclinação para o negó- } \\
\text { cio próprio, já que possui obsessão em provar que tem capacidade } \\
\text { de criar negócios. }\end{array}$ \\
\hline 6 & $\begin{array}{l}\text { Serviço e dedicação a uma } \\
\text { causa (SD) }\end{array}$ & $\begin{array}{l}\text { Caracteriza-se pelo desejo de melhorar o mundo, de servir à } \\
\text { humanidade. Geralmente se constitui de profissões de assistência } \\
\text { ao próximo, como médico, enfermeiro, serviço social, magistério } \\
\text { ou sacerdócio. }\end{array}$ \\
\hline 7 & Desafio puro (DP) & $\begin{array}{l}\text { Refere-se às pessoas que garantem que o sucesso é vencer obstá- } \\
\text { culos impossíveis, conquistar qualquer coisa, vencer adversários } \\
\text { muito fortes. Buscam empregos nos quais tenham que enfrentar } \\
\text { problemas cada vez mais difíceis. }\end{array}$ \\
\hline 8 & Estilo de vida (EV) & $\begin{array}{l}\text { As pessoas desse grupo buscam integrar as necessidades do indi- } \\
\text { víduo, da família e da carreira. Não simplesmente conciliar todas } \\
\text { as coisas, mas conseguir integrá-las como forma de motivação } \\
\text { pessoal. }\end{array}$ \\
\hline
\end{tabular}

Fonte: adaptado de Schein (1996).

De acordo com Schein (1996), as inclinações na vida profissional de uma pessoa podem ser utilizadas como formas de organizar experiências, identificar áreas de contribuição ao longo de sua trajetória, gerar critérios para tipos de trabalho e identificar padrões de ambição e sucesso que a pessoa pode determinar para si mesma. Os trabalhos 
desse autor permitem agregar a preferência profissional efetiva à busca da carreira, contrapondo-a aos estereótipos de sucesso que apontam para o sucesso financeiro e social. As inclinações profissionais servem, portanto, para guiar, balizar, estabilizar e integrar a carreira de uma pessoa (KILIMNIK; CASTILHO; SANT’ANNA, 2006).

\subsection{SATISFAÇÃO COM A VIDA}

Segundo Santos (2003), o bem-estar físico, social e psicológico é um estado desejado pelos seres humanos e, por esse motivo, assunto de interesse de instituições e pesquisadores. Além disso, a busca por esses estados influencia as atitudes das pessoas. A definição de bem-estar na ciência, por sua vez, segue duas tendências: uma que o avalia em termos objetivos, representados por condições de vida, como renda, saúde e moradia; e outra, em termos subjetivos, representados por experiências e aspectos relacionados a aspirações e interesses de natureza individual, ainda que possam ser influenciados por fatores exógenos.

Pesquisas envolvendo bem-estar subjetivo vêm sendo realizadas principalmente por pesquisadores ligados à área da Psicologia, por exemplo, Santos (2003) e Siqueira e Padovan (2008). Esse construto é composto por elementos emocionais e cognitivos (ALBUQUERQUE; TRÓCCOLI, 2004). Enquanto os elementos emocionais referem-se a experiências afetivas positivas e negativas, os cognitivos referem-se à satisfação global quanto aos aspectos gerais da vida do sujeito, ou seja, à satisfação com a vida, que é a variável de bem-estar subjetivo estudada nesta pesquisa.

Para Diener et al. (1985), a satisfação com a vida é influenciada por fatores determinados pelo próprio indivíduo, segundo seus critérios e padrões, e não por um conjunto de fatores pré-determinados por outras pessoas ou instituições. Na perspectiva deste estudo, a satisfação com a vida considera tanto aspectos e estados momentâneos quanto as vivências passadas do indivíduo. A satisfação com a vida é, portanto, uma perspectiva de longo prazo, considerando os valores, os objetivos e as circunstâncias da vida dos sujeitos (PAVOT; DIENER, 1993). Entretanto, como componente cognitivo do bem-estar subjetivo, a satisfação com a vida também precisa considerar a influência do contexto na formação da opinião do indivíduo sobre a sua vida (SCHWARZ; STRACK, 1991). Em outras palavras, a satisfação com a vida considera a situação momentânea, mas sem abandonar uma avaliação global e o contexto do indivíduo, especialmente na apreciação a respeito de sua qualidade de vida, que é um construto de natureza perceptual e subjetivo e, ao mesmo tempo, influenciado 
pela cultura à qual o indivíduo está inserido (DIENER et al., 2000; PAVOT; DIENER, 2008; DIENER; INGLEHART; TAY, 2012).

Um dos fatores que podem interferir na satisfação com a vida do sujeito e na qualidade de vida percebida é o trabalho (CAMPBELL; CONVERSE, RODGERS, 1976 apud WRZESNIEWSKI et al., 1997) e, por consequência, as atitudes em relação à sua carreira. Essa possível influência deve-se ao fato de o trabalho ocupar grande parte do tempo de vida de um indivíduo e impactar tanto na sua situação financeira quanto na forma como se relaciona com outras pessoas, a exemplo da família e dos amigos. Portanto, é importante que o ambiente de trabalho atual e o tipo de carreira seguido sejam capazes de proporcionar bem-estar e satisfação ao indivíduo.

Assim, a satisfação com o trabalho pode variar conforme o sentido que o indivíduo atribui ao seu trabalho. Para Wrzesniewski et al. (1997), um indivíduo pode perceber o seu trabalho como um emprego (preocupado apenas com os benefícios materiais que o trabalho proporciona), carreira (preocupado com os avanços na estrutura ocupacional) ou vocação (o trabalho é inseparável da vida pessoal, ou seja, um “chamado”). No estudo realizado pelos autores, verifica-se que indivíduos para quem o trabalho é uma vocação apresentam maiores níveis de satisfação tanto com o trabalho quanto com a vida.

\section{MÉTODO DE INVESTIGAÇÃO}

\subsection{DELINEAMENTO DA PESQUISA}

Esta pesquisa pode ser definida como quantitativa de natureza descritiva, exploratória e de corte transversal, pois os dados foram coletados uma única vez para a amostra. Para a análise dos dados foram utilizados os softwares SPSS 20.0 (Software Package Used for Statistical Analysis) e SmartPLS 2.0, que utiliza o método de estimação Partial Least Squares, adequado para amostras menores e sem distribuição normal. Para determinar a confiabilidade das escalas foi utilizado o Alfa de Cronbach $(\alpha)$, e para verificar a relação entre as variáveis foi empregada a regressão linear, observando-se o índice de significância estatística de $5 \%(\mathrm{p}<0,05)$, o que permite uma confiança de 95\%. A mostra foi não probabilística, por conveniência, e a coleta foi realizada de forma aleatória, mediante um questionário disponibilizado por meio digital e divulgado em redes sociais e por e-mail durante o ano 2015. 
O questionário para a coleta dos dados foi construído a partir de escalas já existentes e estruturou-se em três partes: na primeira utilizou-se o Inventário de Inclinações Profissionais, proposto por Schein (1996). Esse inventário constitui-se de cinco itens para cada âncora, totalizando 40 itens, que se encontram intercalados na escala. $\mathrm{Na}$ segunda parte, da questão 41 à 45, mensurou-se a satisfação com a vida, utilizando-se a SWLC (Satisfaction With Life Scale), elaborada por Diener et al. (1985), composta por cinco itens. Essas variáveis foram medidas por uma escala do tipo Likert de sete pontos (1 para discordo totalmente e 7 para concordo totalmente). Por último, o questionário continha questões relacionadas a dados socioeconômicos, como idade, sexo, renda e escolaridade. Vale observar que não foi necessária a utilização de uma escala sobre os tipos de carreira tradicional e autodirigida, por ter sido vislumbrada a possibilidade de organizar as inclinações profissionais em torno dessas duas modalidades de carreira, por meio do uso de recursos estatísticos que serão descritos posteriormente.

\section{ANÁLISE E DISCUSSÃO DOS RESULTADOS}

Dos 215 participantes envolvidos na pesquisa, 60,9\% são do sexo feminino e 39,1\% do sexo masculino, com média de idade de 27,9 anos. Em relação à escolaridade, 24,7\% têm ensino superior incompleto, 16,3\% já concluíram o ensino superior e 55,3\% estão cursando pós-graduação. Quanto à renda familiar, o grupo mais representativo $(37,7 \%)$ informou rendimentos entre R \$ 3.018,00 e R \$ 6.005,00, seguido de 21\% com renda entre R $2.900,00$ e R\$ 7.249,99. Apenas 8,4\% informaram renda acima de R\$11.037,00.

A técnica de análise de dados escolhida para associar os modelos de carreira com as inclinações profissionais foi a modelagem de equações estruturais, pois permite a análise das relações existente entre múltiplas variáveis. Para a realização das análises, foi utilizado o software SmartPLS 2.0, que utiliza o método de estimação Partial Least Squares, adequado para amostras menores (<200 casos) e sem distribuição normal (HENSELER; RINGLE; SINKOVICS, 2009; HAIR JUNIOR et al., 2012). Primeiramente, foi verificada a validade do modelo de mensuração. Em seguida, foi verificada a validade do modelo estrutural.

\subsection{MODELO DE MENSURAÇÃO}

O modelo de mensuração foi estimado por meio da análise fatorial confirmatória (AFC), com o algoritmo factor weighting scheme, no SmartPLS, que é mais 
adequado para a verificação de modelos de mensuração (HENSELER; RINGLE; SINKOVICS, 2009). Primeiramente, foram verificados os critérios de qualidade das variáveis latentes reflexivas de primeira ordem, ou seja, as inclinações profissionais.

O primeiro critério avaliado foi a confiabilidade das escalas. Para tanto, foi verificada a confiabilidade composta, que apresentou resultados satisfatórios (confiabilidade $>0,7$ ), exceto para o construto competência técnico-funcional, cuja confiabilidade composta foi de 0,670. Além disso, o coeficiente Alfa de Cronbach também ficou acima do mínimo recomendado na literatura - 0,7 (HAIR JUNIOR et al., 2009) - menos para os construtos competência técnico-funcional e estilo de vida.

O segundo critério avaliado foi a validade convergente, sendo verificadas a variância média extraída e as cargas fatoriais dos indicadores das escalas. As variâncias extraídas ficaram acima de 0,5 para 5 construtos latentes (autonomia/independência; criatividade empreendedora; desafio puro; segurança/ estabilidade; e satisfação com a vida), mas abaixo desse valor para quatro construtos (competência técnica e funcional; estilo de vida; gerência geral; e serviço e dedicação a uma causa). Ao observar as cargas fatoriais dos indicadores dos construtos, verificou-se que alguns indicadores apresentavam cargas fatoriais abaixo de 0,6 para seus respectivos construtos. De acordo com Hair et al. (2009), cargas fatoriais ideais devem estar acima de 0,7, mas cargas entre 0,6 e 0,7 são aceitáveis, desde que os outros critérios sejam atendidos. Portanto, indicadores com cargas fatoriais abaixo de 0,6 foram excluídos das análises. Após essas modificações, os critérios de qualidade dos construtos latentes apresentaram melhoras. A confiabilidade composta ficou acima de 0,7 para todos os construtos, e apenas a competência técnico-funcional ficou com a variância media extraída abaixo de 0,5. Contudo, após as alterações, o Alfa de Cronbach ficou abaixo de 0,7 para as variáveis competência técnico-funcional $(0,472)$, estilo de vida $(0,523)$, gerência geral $(0,679)$ e serviço e dedicação a uma causa $(0,696)$. As cargas fatoriais finais de cada indicador, a variância média extraída, a confiabilidade composta e o Alfa de Cronbach dos construtos podem ser verificados na Tabela 1 . 
Jandir Pauli et al.

Tabela 1 - Carga fatorial, AVE, Confiabilidade composta e Alfa de Cronbach das Inclinações profissionais (continua)

\begin{tabular}{|c|c|c|c|c|c|}
\hline Construto & Item & $\begin{array}{c}\text { Carga } \\
\text { fatorial }\end{array}$ & AVE & $\begin{array}{c}\text { Confia- } \\
\text { bilidade } \\
\text { composta }\end{array}$ & $\begin{array}{c}\text { Alfa de } \\
\text { Cronbach }\end{array}$ \\
\hline \multirow{5}{*}{$\begin{array}{l}\text { Autonomia } \\
\text { /indepen- } \\
\text { dência }\end{array}$} & AI1 <- Autonomia/independência & 0,7091 & \multirow{5}{*}{0,5265} & \multirow{5}{*}{0,8465} & \multirow{5}{*}{0,7735} \\
\hline & AI2 <- Autonomia/independência & 0,8046 & & & \\
\hline & AI3 <- Autonomia/independência & 0,744 & & & \\
\hline & AI4 <- Autonomia/independência & 0,6044 & & & \\
\hline & AI5 <- Autonomia/independência & 0,7507 & & & \\
\hline \multirow{3}{*}{$\begin{array}{l}\text { Competên- } \\
\text { cia técnico- } \\
\text {-funcional }\end{array}$} & TF1 <- Comp. Técnica Funcional & 0,6231 & \multirow{3}{*}{0,46} & \multirow{3}{*}{0,7171} & \multirow{3}{*}{0,4107} \\
\hline & TF3 <- Comp. Técnica Funcional & 0,6417 & & & \\
\hline & TF5 <- Comp. Técnica Funcional & 0,7615 & & & \\
\hline \multirow{5}{*}{$\begin{array}{l}\text { Criati- } \\
\text { vidade } \\
\text { empreen- } \\
\text { dedora }\end{array}$} & CE1 <- Criatividade empreendedora & 0,8192 & \multirow{5}{*}{0,5566} & \multirow{5}{*}{0,8611} & \multirow{5}{*}{0,796} \\
\hline & CE2 <- Criatividade empreendedora & 0,7525 & & & \\
\hline & CE3 <- Criatividade empreendedora & 0,6908 & & & \\
\hline & CE4 <- Criatividade empreendedora & 0,6108 & & & \\
\hline & CE5 <- Criatividade empreendedora & 0,8339 & & & \\
\hline \multirow{5}{*}{$\begin{array}{l}\text { Desafio } \\
\text { puro }\end{array}$} & DP1 <- Desafio Puro & 0,7577 & \multirow{5}{*}{0,5356} & \multirow{5}{*}{0,8512} & \multirow{5}{*}{0,781} \\
\hline & DP2 <- Desafio Puro & 0,707 & & & \\
\hline & DP3 <- Desafio Puro & 0,7154 & & & \\
\hline & DP4 <- Desafio Puro & 0,8318 & & & \\
\hline & DP5 <- Desafio Puro & 0,6327 & & & \\
\hline \multirow{3}{*}{$\begin{array}{l}\text { Estilo de } \\
\text { vida }\end{array}$} & EV1 <- Estilo de Vida & 0,7146 & \multirow{3}{*}{0,5065} & \multirow{3}{*}{0,7548} & \multirow{3}{*}{0,5232} \\
\hline & EV2 <- Estilo de Vida & 0,7078 & & & \\
\hline & EV3 <- Estilo de Vida & 0,7127 & & & \\
\hline \multirow{4}{*}{$\begin{array}{l}\text { Gerência } \\
\text { geral }\end{array}$} & GG2 <- Gerência Geral & 0,7835 & \multirow{4}{*}{0,5045} & \multirow{4}{*}{0,8021} & \multirow{4}{*}{0,6793} \\
\hline & GG3 <- Gerência Geral & 0,7028 & & & \\
\hline & GG4 >- Gerência Geral & 0,6978 & & & \\
\hline & GG5 >- Gerência Geral & 0,6506 & & & \\
\hline \multirow{4}{*}{$\begin{array}{l}\text { Satisfação } \\
\text { com a vida }\end{array}$} & SV1 <- Satisfação com a vida & 0,8228 & \multirow{4}{*}{0,6743} & \multirow{4}{*}{0,8911} & \multirow{4}{*}{0,8538} \\
\hline & SV3 <- Satisfação com a vida & 0,9012 & & & \\
\hline & SV4 <- Satisfação com a vida & 0,8715 & & & \\
\hline & SV5 <- Satisfação com a vida & 0,6696 & & & \\
\hline \multirow{4}{*}{$\begin{array}{l}\text { Segurança/ } \\
\text { estabili- } \\
\text { dade }\end{array}$} & SE1 <- Segurança/Estabilidae & 0,6769 & & & \\
\hline & SE3 <- Segurança/Estabilidae & 0,8116 & م & 10 & ? \\
\hline & SE4 <- Segurança/Estabilidae & 0,849 & 0,6309 & $0,8 / 16$ & 0,8027 \\
\hline & SE5 <- Segurança/Estabilidae & 0,8282 & & & \\
\hline
\end{tabular}




\begin{tabular}{|c|c|c|c|c|c|}
\hline Construto & Item & $\begin{array}{l}\text { Carga } \\
\text { fatorial }\end{array}$ & AVE & $\begin{array}{c}\text { Confia- } \\
\text { bilidade } \\
\text { composta }\end{array}$ & $\begin{array}{c}\text { Alfa de } \\
\text { Cronbach }\end{array}$ \\
\hline \multirow{4}{*}{$\begin{array}{l}\text { Serviço/de- } \\
\text { dicação a } \\
\text { uma causa }\end{array}$} & $\begin{array}{l}\text { SD2 <- Serviço/dedicação a uma } \\
\text { causa }\end{array}$ & 0,662 & \multirow{4}{*}{0,5211} & \multirow{4}{*}{0,8122} & \multirow{4}{*}{0,6959} \\
\hline & $\begin{array}{l}\text { SD3 <- Serviço/dedicação a uma } \\
\text { causa }\end{array}$ & 0,6843 & & & \\
\hline & $\begin{array}{l}\text { SD4 <- Serviço/dedicação a uma } \\
\text { causa }\end{array}$ & 0,8162 & & & \\
\hline & $\begin{array}{l}\text { SD5 <- Serviço/dedicação a uma } \\
\text { causa }\end{array}$ & 0,7154 & & & \\
\hline
\end{tabular}

Fonte: os autores.

O último critério de qualidade verificado foi a validade discriminante. Esta foi confirmada, pois a raiz da variância média extraída foi maior que a correlação entre os construtos (FORNELL; LARCKER, 1981), conforme a Tabela 2.

Tabela 2 - validade discriminante das inclinações profissionais

\begin{tabular}{|c|c|c|c|c|c|c|c|c|c|}
\hline & 1 & 2 & 3 & 4 & 5 & 6 & 7 & 8 & 9 \\
\hline $\begin{array}{l}1 \text {-Autonomia/ } \\
\text { independência }\end{array}$ & 0,726 & & & & & & & & \\
\hline $\begin{array}{l}2 \text { - Competên- } \\
\text { cia técnico-fun- } \\
\text { cional }\end{array}$ & 0,246 & 0,678 & & & & & & & \\
\hline $\begin{array}{l}3 \text { - Criativida- } \\
\text { de empreende- } \\
\text { dora }\end{array}$ & 0,462 & 0,349 & 0,746 & & & & & & \\
\hline $\begin{array}{l}4-\text { Desafio } \\
\text { puro }\end{array}$ & 0,218 & 0,315 & 0,230 & 0,732 & & & & & \\
\hline $\begin{array}{l}5 \text { - Estilo de } \\
\text { vida }\end{array}$ & 0,280 & 0,236 & 0,206 & 0,131 & 0,712 & & & & \\
\hline $\begin{array}{l}\text { 6-Gerência } \\
\text { geral }\end{array}$ & 0,351 & 0,100 & 0,272 & 0,342 & 0,077 & 0,710 & & & \\
\hline $\begin{array}{l}7 \text { - Satisfação } \\
\text { com a vida }\end{array}$ & 0,024 & 0,199 & 0,067 & 0,087 & 0,064 & 0,102 & 0,821 & & \\
\hline $\begin{array}{l}8 \text { - Segurança/ } \\
\text { estabilidade }\end{array}$ & $-0,252$ & 0,230 & $-0,147$ & $-0,067$ & 0,132 & $-0,027$ & 0,061 & 0,794 & \\
\hline $\begin{array}{l}9 \text { - Serviço/ } \\
\text { dedicação a } \\
\text { uma causa }\end{array}$ & 0,139 & 0,347 & 0,312 & 0,345 & 0,219 & 0,064 & 0,179 & 0,008 & 0,722 \\
\hline
\end{tabular}

Em seguida, foram verificados os critérios de qualidade para os construtos latentes carreira tradicional e carreira autodirigida. Estes foram considerados construtos 
reflexivo-formativos de segunda ordem, o que significa que são construtos multidimensionais, formados por outros construtos reflexivos de primeira ordem. O primeiro deles é carreira autodirigida, construto formado por autonomia e independência, criatividade empreendedora, desafio puro, serviço/dedicação a uma causa, estilo de vida e gerência geral. O segundo construto multidimensional encontrado foi denominado carreira tradicional e inclinações profissionais, composto por: segurança/estabilidade e competência técnico-funcional.

Foi, portanto, utilizada a abordagem de indicadores repetidos, em que as variáveis observáveis são associadas às suas respectivas variáveis latentes de primeira ordem e também à variável latente de segunda ordem (BECKER; KLEIN; WETZELS, 2012).

Para esse tipo de construto considera-se inadequada a verificação da confiabilidade composta, Alfa de Cronbach e variância média extraída, pois é um construto formado por dimensões diferentes entre si (DIAMANTOPOULOS; WINKLHOFER, 2001; HAIR JUNIOR, RINGLE; SARSTEDT, 2011). Portanto, os critérios de qualidade foram verificados segundo o peso dos indicadores, multicolinearidade e validade convergente, conforme diretrizes da literatura (BECKER; KLEIN; WETZELS, 2012; HAIR JUNIOR et al., 2014). Os pesos ficaram em: autonomia/independência $=0,348$ ( $\mathrm{t}=5,661)$; criatividade empreendedora $=0,369(\mathrm{t}=8,137)$; desfio puro $=0,310$ $(\mathrm{t}=5,772)$; serviço/ dedicação a uma causa $=0,206(\mathrm{t}=3,442)$; estilo de vida=0,125 ( $t=3,090)$; gerência geral $=0,213(t=4,661)$, para carreira autodirigida, e segurança estabilidade=0,863 $(\mathrm{t}=14,418)$; competência técnico-funcional=0,343 $(\mathrm{t}=4,437)$, para carreira tradicional.

De forma geral, os resultados encontrados permitem aceitar as medidas e os construtos utilizados, uma vez que os testes do modelo de mensuração apresentaram resultados aceitáveis.

\subsection{ANÁLISE DO MODELO ESTRUTURAL}

Após o modelo de mensuração ter sido considerado adequado, o modelo estrutural proposto foi avaliado com o algoritmo path weighting scheme, no SmartPLS (HENSELER; RINGLE; SINKOVICS, 2009). Os critérios verificados foram o coeficiente de determinação $\left(\mathrm{R}^{2}\right)$ e os coeficientes de caminho (ß) que representam a força e o sinal da relação entre as variáveis, cuja significância foi obtida pelo procedimento bootstrapping, com 1.000 subamostras (HENSELER; RINGLE; SINKOVICS, 2009). Os resultados estão descritos a seguir. 


\subsubsection{Influência da carreira autodirigida sobre satisfação com a vida}

Os resultados demonstram que, embora o modelo tenha mostrado um baixo poder de explicação sobre a variação da satisfação com a vida $\left(\mathrm{R}^{2}=0,028\right)$, foi possível verificar que a influência da carreira autodirigida $(\S=0,131)$ e da carreira tradicional $(ß=0,110)$ sobre a satisfação com a vida, apesar de positiva, não foi significante $(\mathrm{t}=0,837 ; \mathrm{t}=0,779$, respectivamente).

No Diagrama 1 estão representados o modelo e as relações entre as variáveis.

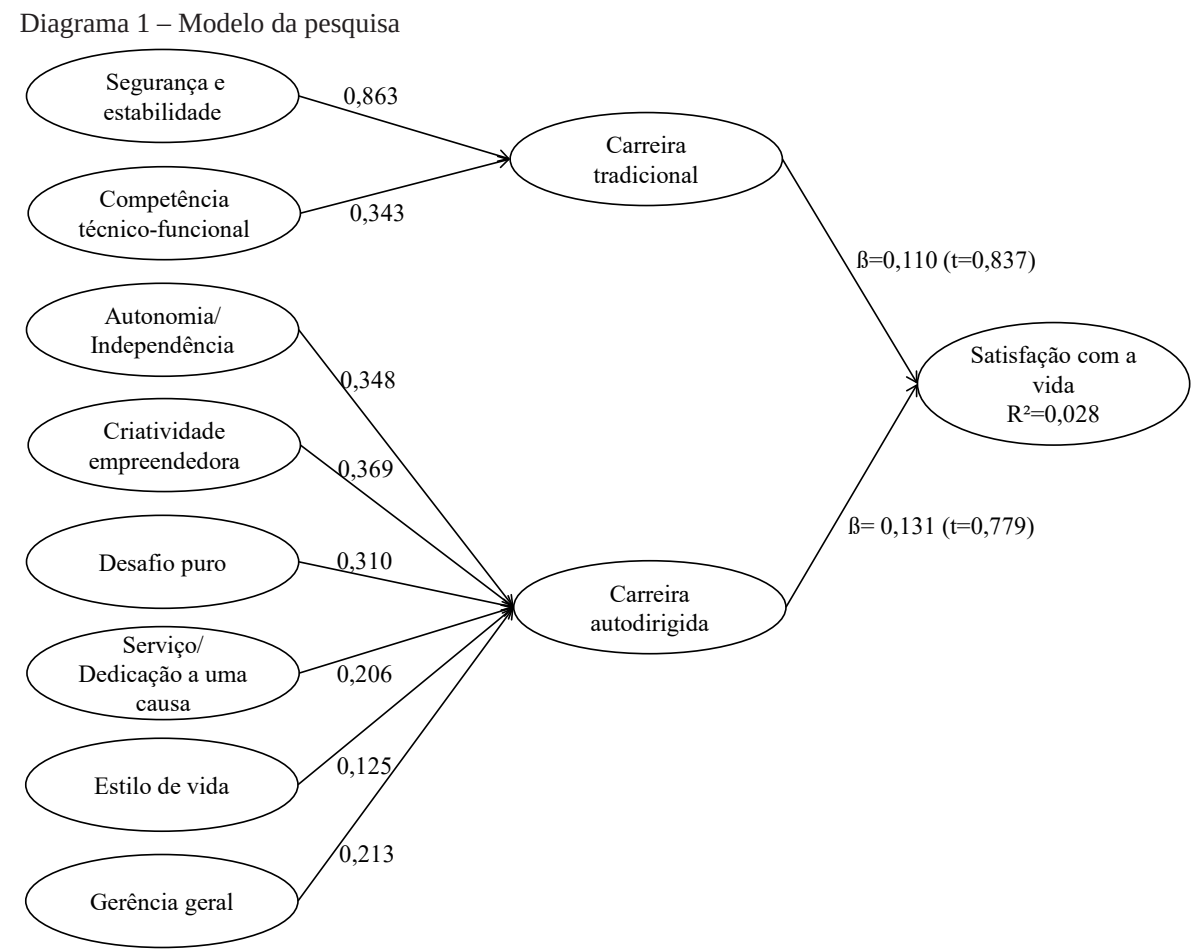

Fonte: os autores.

Após a análise fatorial, foi realizada uma análise descritiva considerando os construtos de inclinações profissionais e satisfação com a vida. A média de satisfação geral com a vida foi de 5,049, mostrando que os indivíduos avaliados fazem uma avaliação bastante positiva da sua vida. Quanto às inclinações, a análise descritiva mostrou que a maior média foi atribuída ao estilo de vida $(5,00)$, com desvio padrão ( $\sigma$ ) de 1,023 , seguida por serviço e dedicação a uma causa $(4,88, \sigma=1,050)$, desafio puro $(4,794, \sigma=1,110)$ e competência técnico-funcional $(4,791, \sigma=0,824)$. As médias 
mais baixas foram gerência geral $(4,072, \sigma=1,071)$ e criatividade empreendedora $(4,237, \sigma=1,393)$. As questões que receberam as melhores médias foram "Sonho em ser tão bom no que faço de tal forma que meus conhecimentos especializados sejam constantemente procurados" $(6,065, \sigma=1,074)$ e "Sinto-me plenamente realizado em meu trabalho quando sou capaz de empregar minhas habilidades e meus talentos especiais” (5,693, $\sigma=1,300)$, ambas relacionadas com a inclinação competência técnico funcional. As médias mais baixas foram atribuídas às questões "Prefiro deixar minha organização do que aceitar um emprego que me afaste da trajetória de gerência geral” (3,177, $\sigma=1524)$, da inclinação gerência geral e "Montar meu próprio negócio é mais importante para mim do que atingir uma alta posição gerencial como empregado" $(3,705, \sigma=1,917)$ e "Sinto-me bem-sucedido em meu trabalho apenas quando posso criar ou construir alguma coisa que seja inteiramente de minha autoria” (3,818, $\sigma=1,573$ ), ambas relacionadas com criatividade empreendedora.

A comparação entre o resultado da análise do modelo estrutural e das frequências dos construtos permite concluir que as inclinações profissionais dos estudantes de programas de pós-graduação em Administração pesquisados estão mais voltadas à carreira autodirigida, com destaque para estilo de vida, dedicação a uma causa e desafio puro. Para Schein (1996), essas inclinações indicam que os indivíduos projetam que suas carreiras exercitem a superação constante de obstáculos, que as tarefas e atribuições estejam associadas a algum tipo de serviço social, útil à coletividade, e que a carreira contribua para o equilíbrio entre a dedicação ao trabalho e a manutenção dos laços familiares e afetivos.

Por fim, mediante a regressão linear, a satisfação com a vida foi estabelecida como variável dependente, confrontada com as 40 perguntas do questionário das inclinações profissionais. Os resultados mostram um “r” ajustado de ,192. Apenas duas questões mostraram significância: A questão "Sinto-me mais realizado em meu trabalho quando tenho total liberdade para definir minhas próprias tarefas, horários e procedimentos”, da âncora autonomia e independência $(\mathrm{p}<0,05$ e $ß=0,168)$ e "Sinto-me mais realizado em minha carreira quando soluciono problemas insolúveis ou venço o que aparentemente é impossível de ser vencido”, da âncora desafio puro ( $p<0,05$ e $ß=-0,171)$.

A intenção da escala de satisfação com a vida avalia o grau de satisfação global com a vida a partir de critérios subjetivos (PAVOT; DIENER, 2008). Nesse espectro, a carreira, mesmo que resumida a apenas um aspecto da vida dos indivíduos, pode ter implicações para a satisfação com a vida. Por isso, avaliar a relação entre o modelo de carreira e sua relação com a satisfação com a vida pode oferecer pistas importantes sobre as expectativas individuais e organizacionais que repousam 
sobre as escolhas e inclinações de carreira. Assim como a carreira, a satisfação com a vida é uma perspectiva de longo prazo e considera não somente as circunstâncias do cotidiano dos sujeitos, mas seus valores e objetivos de vida (PAVOT; DIENER, 1993).

Nesse sentido, os elementos inscritos nas questões "Sinto-me mais realizado em meu trabalho quando tenho total liberdade para definir minhas próprias tarefas, horários e procedimentos" e "Sinto-me mais realizado em minha carreira quando soluciono problemas insolúveis ou venço o que aparentemente é impossível de ser vencido" demonstram como a autonomia e o desafio incidem na avaliação da satisfação com a vida. Em outros termos, quando a carreira consegue oferecer autonomia e desafio, indivíduos sentem-se mais satisfeitos com a vida. Esses resultados estão na mesma direção das conclusões de Stone, Deci e Ryan (2009), quando mostram que quanto maior a autonomia de um sujeito, maior é a sua satisfação no trabalho.

Além disso, a análise mostra que embora a maioria das inclinações de carreira não apresente influências na satisfação com a vida, a carreira autodirigida demonstra possuir dimensões subjetivas que precisam ser consideradas, dado que influenciam a avaliação global que os sujeitos fazem da sua vida. Isso remete à discussão sobre a relação entre satisfação com a vida e carreira autodirigida para demonstrar que as definições por modelos de carreira não são elementos secundários ou marginais nas escolhas individuais, mas estão ligadas aos valores e crenças individuais, marcando sua percepção da experiência vivida.

Por fim, ao articular inclinações profissionais e modelos de carreira com a satisfação com a vida, este estudo permitiu os aspectos específicos que relacionam as lógicas profissionais, seguidamente marcadas por estímulos externos. Com isso, o componente cognitivo da satisfação com a vida passa a estar articulado de forma direta com o contexto de atuação do indivíduo (SCHWARZ; STRACK, 1991), estabelecendo os aspectos interrelacionais entre as lógicas de atuação objetiva e subjetivas dos sujeitos nas suas escolhas de carreira.

\section{CONSIDERAÇÕES FINAIS}

Neste estudo buscou-se identificar a relação entre modelos de carreira, inclinações profissionais e autopercepção de satisfação com a vida. Os principais achados foram os seguintes: as inclinações profissionais mais próximas do modelo de carreira tradicional foram autonomia e independência, criatividade empreendedora, desafio puro, serviço e dedicação a uma causa e estilo de vida e gerência geral. Por outro lado, 
apenas as inclinações segurança e estabilidade e competência técnico-funcional foram associadas à carreira tradicional.

Uma segunda conclusão é de que tanto as inclinações quanto os modelos (tradicional ou autodirigido) de carreira não influenciam significativamente a satisfação com a vida, embora determinadas dimensões das inclinações profissionais, como autonomia, independência e desafio puro mostrem influência significativa. Essa evidência abre uma importante discussão sobre as possibilidades de gerenciamento da carreira de maneira que esta tenha elementos relacionados à autonomia e independência, assim como desafios que possam contribuir para a satisfação com a vida e, possivelmente, também, para a qualidade no trabalho, indo ao encontro das proposições teóricas deste estudo.

A partir dessas conclusões, é possível afirmar que nesta pesquisa cumpriram-se os objetivos pela definição do grau de correlação entre as variáveis propostas. Dessa forma, embora com a avaliação da necessidade de aprofundar este estudo com um público mais heterogêneo e em maior número, os resultados lançam luzes para a compreensão de três temas centrais da gestão de pessoas nas organizações: a autopercepção dos indivíduos sobre o modelo de carreira que segue, suas inclinações profissionais e a interferência destas na satisfação com a vida.

\section{REFERÊNCIAS}

ALBUQUERQUE, A. S.; TRÓCCOLI, B. T. Desenvolvimento de Uma Escala de Bem-Estar Subjetivo. Psicologia: Teoria e Pesquisa, v. 20, n. 2, p. 153-164, maio/ ago. 2004.

ANDRADE, G. A. Carreira tradicional versus carreira proteana: um estudo comparativo sobre a satisfação com a profissão, carreira e emprego. 2009. Dissertação (Mestrado em Gestão Estratégica de Organizações)-Fundação Mineira de Educação e Cultura, Minas Gerais, 2009.

ARTHUR, M. B.; ROUSSEAU, D. M. The boundaryless career. Oxford: Oxford University Press, 1996.

BARUCH, Y. Transforming careers: from linear to multidirectional career paths: organizational and individual perspectives. Career development international, v. 9, i. 1, p. 58-73, 2004. 
BECKER, J. M.; KLEIN, K.; WETZELS, M. Hierarchical latent variable models in PLS-SEM: Guidelines for using reflective-formative type models. Long Range Planning, v. 45, p. 359-394, 2012.

BENDASSOLLI, P. F. Recomposição da relação sujeito-trabalho nos modelos emergentes de carreira. RAE, São Paulo, v. 49, n. 4, dez. 2009. Disponível em: <http:// www.scielo.br/scielo.php?script=sci_arttext\&pid=S003475902009000400003\&lng=en\&nrm=iso $>$. Acesso em: 09 jul. 2014.

CAMPBELL, A.; CONVERSE, P. E.; RODGERS, W. L. The quality of American life. New York: Russell Sage Foundation, 1976.

DIAMANTOPOULOS, A.; WINKLHOFER, H. M. Index construction with formative indicators: an alternative to scale development. Journal of Marketing Research, v. 38, i. 2, p. 269-277, 2001.

DIENER, E. et al. Positivity and the construction of life satisfaction judgments: global happiness is not the sum of its parts. Journal of Happiness Studies, v. 1, i. 2, p. 159-176, 2000.

DIENER, E. et al. The Satisfaction With Life Scale. Journal of Personality Assessment, v. 49, i. 1, p. 71-75, 1985.

DIENER, E.; INGLEHART, R.; TAY, L. Theory and validity of life satisfaction scales. Social Indicators Research, 2012.

DUTRA, J. S. Administração de carreira: uma proposta para repensar a gestão de pessoas. São Paulo: Atlas, 1996.

FONTENELLE, I. A. Eu Proteu: A auto-gestão de carreira entre fatos e mitos. In: ENCONTRO NACIONAL DOS PROGRAMAS DE PÓS-GRADUAÇÃO EM ADMINISTRAÇÃO, 29., 2005, Brasília, DF. Anais... Brasília, DF, 2005.

HAIR, J. F. et al. An assessment of the use of partial least squares structural equation modeling in marketing research. Journal of the Academy of Marketing Science, v. 40, p. 414-433, 2012.

HAIR, J. F. et al. Análise multivariada de dados. 6. ed. Porto Alegre: Bookman, 2009. 
HAIR, J. F. et al. A primer on partial least squares structural equations modeling (PLS-SEM). Los Angeles: SAGE, 2014.

HAIR, J. F.; RINGLE, C. M.; SARSTEDT, M. PLS-SEM: Indeed a silver bullet. Journal of Marketing Theory and Practice, v. 19, i. 2, p. 139-152, 2011.

HALL, D.; MIRVIS, P. The career is dead, long live the career: A relational approach to careers. San Francisco: Jossey-Bass, 1996.

HALL, D. T. Careers in and out of organizations. California: Sage Publications, 2002.

HENSELER, J.; RINGLE, C. M.; SINKOVICS, R. R. The use of partial least squares path modeling in International Marketing. Advances in International Marketing, v. 20, p. 277-319, 2009.

KILIMNIK, Z.; CASTILHO, I.; SANT’ANNA, A. Carreiras em Transformação: um estudo de trajetórias, âncoras e metáforas de carreira em associação a representações de competências profissionais. Comportamento Organizacional e Gestão, v. 12, n. 2, p. 257-280, jan./jun. 2006.

KILIMNIK, Z.; RODRIGUES, C.; BOUZADA, V. Estilo de vida e segurança: seriam essas as âncoras dos futuros detentores de "carreiras proteanas ou sem fronteiras? Um estudo comparativo entre alunos de graduação e de mestrado em Administração. Convibra, 2007. Disponível em: <http://www.convibra.com.br/2007/ congresso/artigos/ 160.pdf >. Acesso em: 20 mar. 2014.

MARTINS, H. T. Gestão de carreiras na era do conhecimento: abordagem conceitual \& resultados de pesquisa. Rio de Janeiro: Qualitymark, 2001.

MCDONALD, P.; BROWN, K.; BRADLEY, L. Have traditional career paths given way to protean ones? Evidence from senior managers in the Australian public sector. Career Development International, v. 10, i. 2, p. 109-129, 2005.

NUNNALLY, J. C. Psychometric Theory. 2. ed. New York: McGraw, 1978.

PAVOT, W.; DIENER, E. Review of the satisfaction with life scale. Psychological Assessment, v. 5, i. 2, p. 164-172, 1993.

PAVOT, W.; DIENER, E. The satisfaction with life scale and the emerging construct of life satisfaction. Journal of Positive Psychology, v. 3, p. 137-152, 2008. 


\section{SANTOS, A. T. Controle percebido, senso de auto-eficácia e satisfação com a} vida: um estudo comparativo entre homens e mulheres pertencentes a três grupos de idade. 2003. Tese (Doutorado em Educação)-Universidade Estadual de Campinas, Campinas, 2003.

SCHEIN, E. H. Identidade profissional. Como ajustar suas inclinações e suas opções de trabalho. Tradução Margarida D. Black. São Paulo: Nobel, 1996.

SCHWARZ, N. et al. The satisfaction with life scale and the emerging construct of life satisfaction. Journal of Positive Psychology, v. 3, p. 137-152, Mar. 2008.

SCHWARZ, N.; STRACK, F. Evaluating one's life: a judgment model of subjective wellbeing. In: STRACK, F.; ARGYLE, N.; SCHWARZ, N. (Ed.). Subjective WellBeing: an interdisciplinary perspective. Oxford: Pergamon Press, 1991.

SIQUEIRA, M. M. M.; PADOVAN, V. A. R. Bases Teóricas de Bem-Estar Subjetivo, Bem-Estar Psicológico e Bem-Estar no Trabalho. Psicologia: Teoria e Pesquisa, v. 24, n. 2, p. 201-209, 2008.

STONE, D. N.; DECI, E. L.; RYAN, R. M. Beyond talk: Creating autonomous motivation through self-determination theory. Journal of General Management, v. 34, i. 3, p. 75, 2009.

WRZESNIEWSKI, A. et al. Jobs, Careers, and Callings: People’s Relations to Their Work. Journal of Research in Personality, v. 31, p. 21-33, 1997.

\section{Agradecimentos}

Agradecemos à Fundação de Amparo à Pesquisa do Estado do Rio Grande do Sul (FAPERGS) (Termo de outorga 2328-2551/14-9) e ao Conselho Nacional de Desenvolvimento Científico e Tecnológico (CNPq) (Processo 447940/2014-7) pelo apoio financeiro para a realização da pesquisa.

\section{Como citar este artigo:}

ABNT

PAULI, Jandir et al. Modelos de carreira, inclinações profissionais e satisfação com a vida. RACE, Revista de Administração, Contabilidade e Economia, Joaçaba: Ed. Unoesc, v. 16, n. 1, p. 305-326, jan./abr. 2017. Disponível em: <http://editora. unoesc.edu.br/index.php/race>. Acesso em: dia/mês/ano. 
Jandir Pauli et al.

\section{APA}

Pauli, J., Kilimnik, Z. M., Ruffatto, J., \& Lazzarotto, J. (2017). Modelos de carreira, inclinações profissionais e satisfação com a vida. RACE, Revista de Administração, Contabilidade e Economia, 16(1), 305-326. Recuperado em dia/mês/ano, de http:// editora.unoesc.edu.br/index.php/race 